\title{
RELIEF OF MERCURY AND THE MOON: FROM MORPHOMETRY TO MORPHOLOGICAL MAPPING
}

\author{
A. Yu. Zharkova ${ }^{1,2}$, M. M. Kolenkina ${ }^{1}$, A. A. Kokhanov $^{1}$, I. P. Karachevtseva ${ }^{1}$ \\ ${ }^{1}$ Moscow State University of Geodesy and Cartography (MIIGAIK), MIIGAiK Extraterrestrial Laboratory, Moscow, Russia - \\ a_zharkova@miigaik.ru, maria_kolenkina@list.ru, a_kokhanov@miigaik.ru, i_karachevtseva@miigaik.ru \\ ${ }^{2}$ Moscow State University Sternberg Astronomical Institute, Moscow, Russia
}

KEY WORDS: Mercury, The Moon, Relief features, Morphology, Planetary cartography

\begin{abstract}
:
The MESSENGER mission (2011-2015) gives us an opportunity to gain new knowledge about Mercury which is still the least explored planet of the terrestrial group. The quality of the new data makes it possible to carry out comparative planetological analysis with the Moon - our nearest neighbour and Mercury's most resembling celestial body in Solar System but placed in different conditions. Our work focuses on calculation of morphometric parameters of relief characteristics for Mercury and the Moon, based on the newest DEMs, and creation of morphological maps, which help us to identify common patterns in planetary surface and reveal hidden details like cryptomaria.
\end{abstract}

\section{INTRODUCTION}

Estimates of values of various morphometric characteristics are widely used for explanation of Earth's geomorphology. Such parameters as relative topographic position (RTP), interquartile range of the second derivative of heights (IQR) and land-surface curvatures allow us to distinguish and classify geological features and give a complex view on processes of their formation. However, methods that are usually applied to our planet can be effective for other celestial bodies with solid surface. For example, due to measurements of various morphometric parameters and their subsequent morphological interpretation:

- a number of spiral structures on the surfaces of Venus and Mars were identified (Florinsky, 2008);

- lunar cryptomaria - ancient volcanic plains hidden behind the newest craters - were explored (Kreslavsky et al., 2013);

- global maps of topographic roughness of Mars (Kreslavsky and Head, 2000) and the Moon (Rosenburg et al., 2011) were created.

Calculations of Mercury morphometric parameters also were performed earlier based on laser altimetry data (Kreslavsky et al., 2014) and results of photogrammetric processing of stereo images (Zharkova et al., 2018) obtained by MESSENGER. But now our possibilities have expanded even more because we can explore Mercury surface by DEMs with different resolution and coverage. Open access to the latest high-resolution data makes it possible to compare Mercury relief features (even relatively small) with similar objects on the Moon. Thereby, the main goal of our study is to calculate values of various morphometric parameters of Mercury and the Moon at two scale levels global and detail - for the further comparative planetary analysis and mapping.

\section{SURVEY}

At both scale levels of study we apply methods of spatial data processing, mapping, cartometric and morphometric analyses.

\subsection{Data}

For Mercury we use the newest high resolution MESSENGER DEMs: 1. the first global Mercury DEM with resolution 665 $\mathrm{m} /$ pixel (Becker et al., 2016); 2. DEMs on four Mercury quadrants with resolution $\sim 222 \mathrm{~m} /$ pixel and vertical accuracy of about $30 \mathrm{~m}$ (Preusker et al., 2017).

For the Moon we choose the global DEM GLD100 (Scholten et al., 2012) with a resolution of $118 \mathrm{~m} / \mathrm{pixel}$ and full coverage of polar regions.

Also we visually surveyed LROC image mosaics (Robinson et al., 2010) and MESSENGER MDIS (Hawkins et al., 2007) images in order to verify the results of our automatic calculations.

All DEMs listed above are obtained as result of photogrammetric image processing, not altimetry data. Because maps based on processing of photogrammetric DEM have better isotropy than maps developed using altimeter data, which characterize the surface roughness in the main direction along meridional-oriented orbits. For this reason DEMs obtained by photogrammetric methods have some advantage in calculation of morphometric parameters.

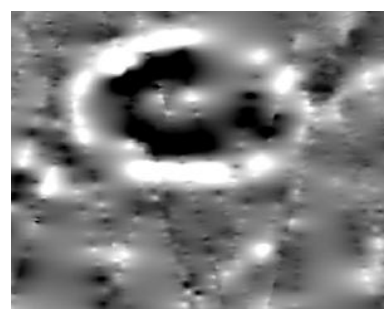

a)

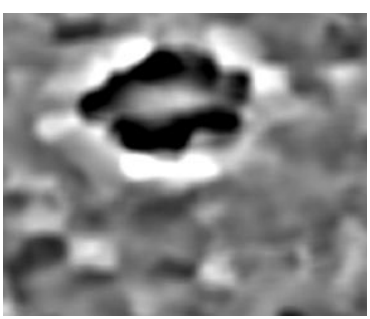

b)
Figure 1. The results of RTP's calculation by different DEMs:

a) a small fragment of DEM obtained by MLA data (with resolution $665 \mathrm{~m} / \mathrm{pixel}$ ), interpolation of individual tracks causes artifacts that cross the crater; b) a fragment of the global DEM at the same site with the same resolution 
Nevertheless, the DEM formed from laser altimetry data can be used to create local morphological maps of the northern polar region of Mercury (Fig. 2). Laser track coverage (due to the particular qualities of the MESSENGER orbit) is maximal in this area of the planet and gives a clear high-resolution image of relief compared to other data on the same territory.

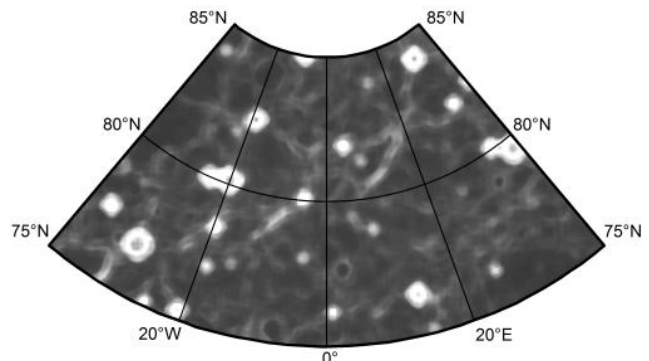

a)

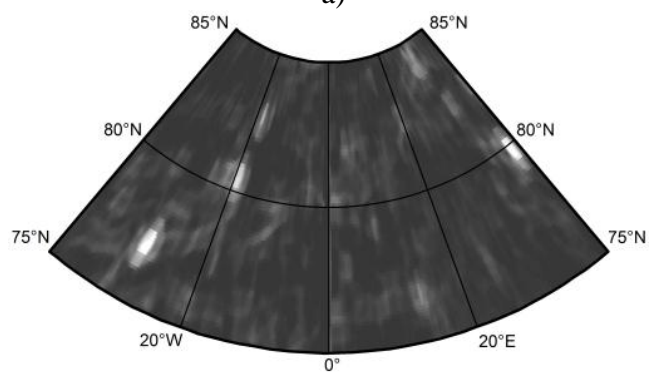

b)

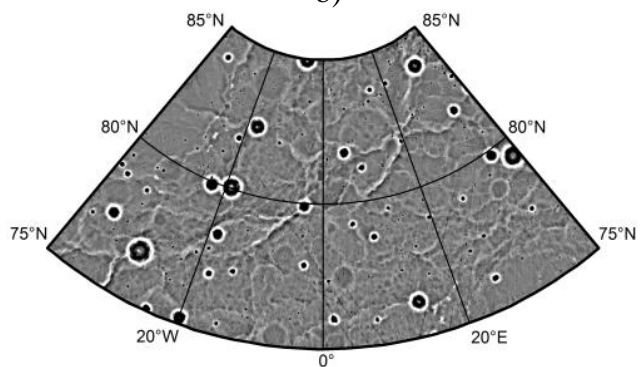

c)

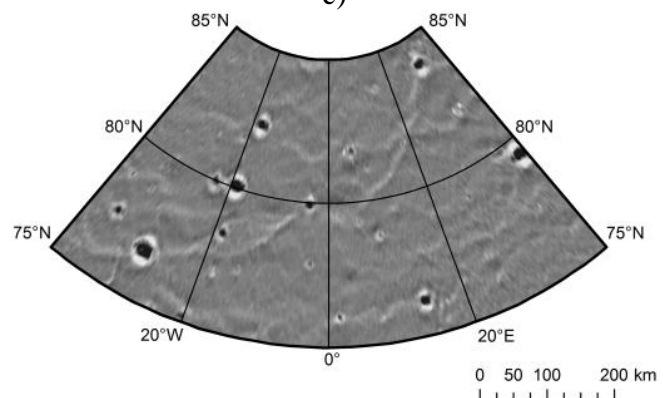

d)

Figure 2. Demonstration of the potential of using MLA data near the North Pole of Mercury: a) IQR calculated by DEM with a resolution of $250 \mathrm{~m} /$ pixel (MLA); b) IQR calculated by global DEM with a resolution of $665 \mathrm{~m} /$ pixel (MDIS WAC and

NAC); RTP calculated by DEM with a resolution of 250 m/pixel (MLA); d) RTP calculated by global DEM with a resolution of $665 \mathrm{~m} /$ pixel (MDIS WAC and NAC)
In the future it is possible to use MLA data or their combination with other digital products (fusion DEMs) for detailed morphological mapping of regions of interest near the North Pole.

\subsection{Parameters}

Depending on the tasks we calculate different morphometric parameters of the surface. For the purposes of our study we mostly use two of them:

- Interquartile range of the second derivative of heights. To calculate this parameter we use a previously developed tool integrated into the ArcGIS software (Kokhanov et al., 2016). Interquartile range gives us the global patterns of planetary relief - distribution of smooth and rough areas - but at the same time, it points to geological age of some features and distinguishes old hidden structures that are not visible on images.

- Relative topographic position (RTP). This parameter means that topographic position of each pixel of processed DEM is identified with respect to its local neighbourhood. RTP is almost identical to the Topographic Position Index (TPI), but its values are normalized (converted to the range from 0 to 1 ) for ease of use. Results are suitable for automatic detection of crater rims and depressions (concave/convex objects).

The choice of these parameters is justified by the fact that they are quickly calculated by ArcGIS and clearly show the macrorelief forms (such as smooth volcanic plains, rough intercrater plains, rims of craters, relief depressions and tops of hills) without difficulties in interpretation of results.

Furthermore, both parameters have already been used for transition from numerical values of morphometric parameters to morphological classes on Earth (Jenness J., 2006) and development of the Moon maps (Kokhanov et al., 2013), which confirms the correctness of the chosen approach.

Initially, the morphological mapping was planned on the basis of only one of the studied morphometric parameters. After calculating and normalizing the results, it was supposed to perform a comparative analysis and decide which of the two parameters would be better for our purposes. However, during the comparison, the selected parameters revealed a number of advantages and disadvantages. So we decide to use the combination of two parameters for morphological mapping, because it is impossible to ignore one useful parameter in favour of another.

But in this case we face a significant amount of information at detailed level. We have to set limits and perform the selection of regions of the greatest interest for local morphological mapping.

\subsection{Regions of interest}

For the Moon studies we decided to explore region including part of Mare Orientale and the northern part of South PoleAitken basin (Fig.3). The South Pole-Aitken basin is the large impact structure on Moon's far side, which attracts strong attention of geomorphologists and geologists (Ivanov et al., 2018).

This region contains a wide range of relief features, which are found on Mercury too: smooth volcanic plains (light and dark), inter-crater hummocky plains, big multi-ring impact basins (crater Apollo, for example), and chains of secondary craters. 


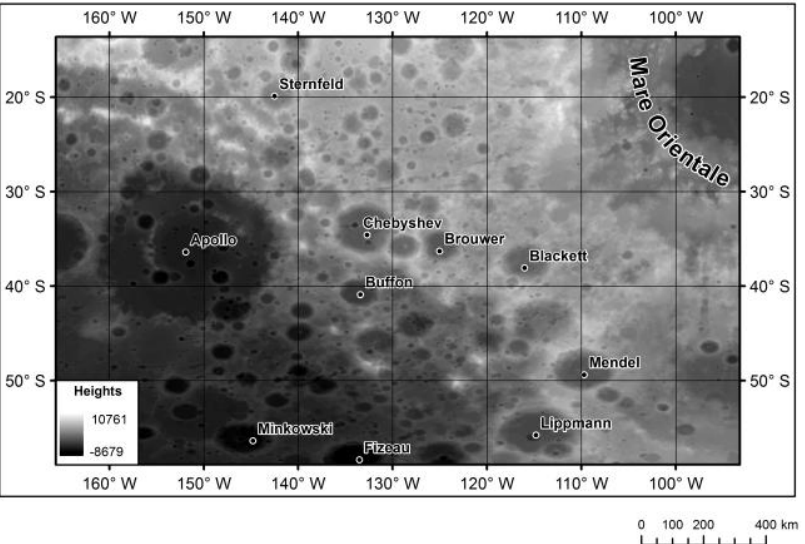

Figure 3. Part of global lunar DEM GLD100 (118 m/pixel) on the northern region of South Pole-Aitken basin

For Mercury studies Kuiper quadrant (H-06) was chosen (Fig.4). Hermian surface is traditionally divided into 15 parts, named after the most pronounced relief details, located on them. This region between longitudes $288^{\circ} \mathrm{E}-360^{\circ} \mathrm{E}$ and latitudes $22.5^{\circ} \mathrm{N}-22.5^{\circ} \mathrm{S}$ is characterized by mixed relief with prevalence of crater materials and named after high-albedo Kuiper crater with a diameter $55 \mathrm{~km}$. The selected region is covered with a high-resolution DEM (222 m/pixel).

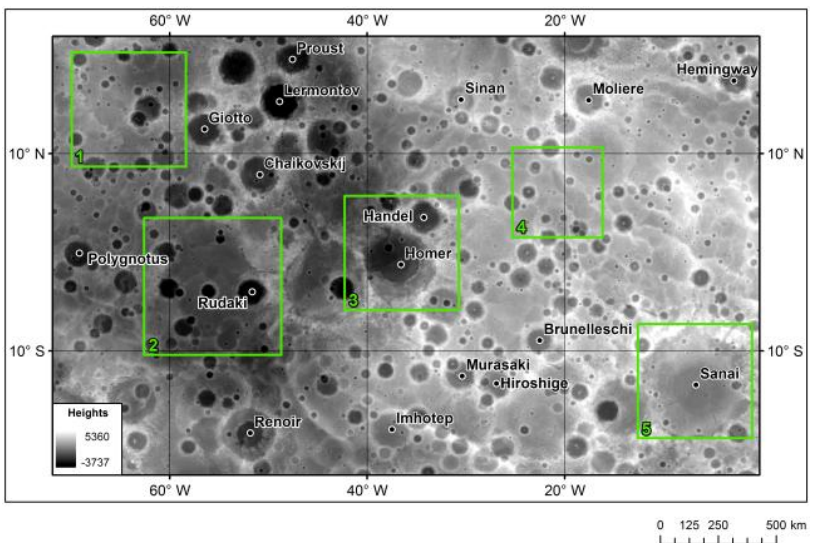

Figure 4. Mercury high-resolution DEM ( $222 \mathrm{~m} /$ pixel) on Kuiper quadrant

The green squares In Figure 2 show common types of Mercury's surface, such as: 1 . an example of typical inter-crater hummocky plain; 2. an example of smooth plain (Sihtu Planitia); 3. Homer multi-ringed basin (diameter $319 \mathrm{~km}$ ); 4 . Santa Maria scarp (length $227 \mathrm{~km}$ ); 5. large Sana crater (diameter $490 \mathrm{~km}$ ).

These sites were used as training data for experiments with zoning by supervised classification technique. The selection of areas with typical landforms is prerequisite for the implementation of this classification method, in particular, for determination of range of numerical values of morphometric parameters associated with particular types of planetary relief.

\section{MAIN RESULTS}

During testing of automated morphological classification on chosen sites it turned out that different parameters work better with different terrain objects (Table 1). The minimal values of the interquartile range of the second derivative of heights, for example, point to smooth areas with low values of topographic roughness, whereas low values of relative topographic position are usually associated with depressions.

\begin{tabular}{|l|c|}
\hline \multicolumn{1}{|c|}{ Class on map } & Morphometric parameter \\
\hline Depression & RTP \\
Smooth plains & IQR \\
Hummocky plains & IQR \\
Slopes of highland & IQR \\
Peaks & RTP \\
\hline
\end{tabular}

Table 1. Preferred morphometric parameters for relief forms

The IQR works better at the global level with big objects, especially when we calculating it on a large basis, which provides smoothing and generalization of results (Fig.5a) without losing valuable information about the relief in noise as happens on a small basis.

The RTP, on the contrary, is more resistant to the noise and continues to clearly display relatively small objects even when the window size is reduced (Fig.5b). This parameter has the potential for mapping particular objects of the relief at a detailed level, for example, craters with a complex structure (with terraces, central peaks and additional rims).

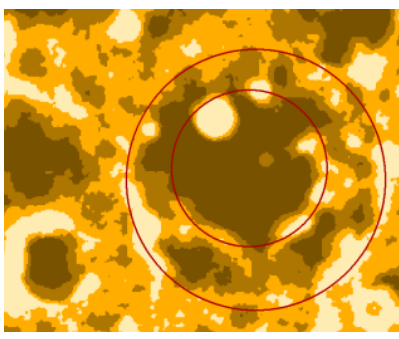

a)

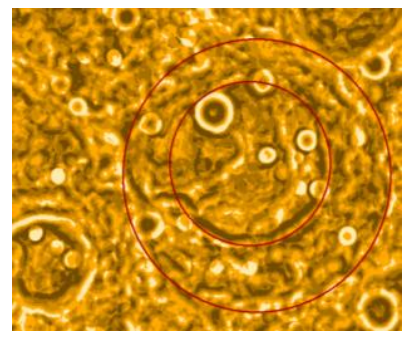

b)
Figure 5. The morphology of Homer crater, obtained by processing of DEM on Kuiper quadrant ( $222 \mathrm{~m} /$ pixel) and expressed by classified relief parameters: a) IQR - dark areas show smooth plains; b) RTP - dark areas show depressions

In order to preserve the advantages of both methods, a new approach was adopted, based on a combination of calculations. At first, the pixel values of raster of relief parameters were normalized and reduced to the convenient range (from zero to one), in which values of RTP express extremes - depressions and peaks, and IQR is responsible for the average values which corresponding to the plains and lower slopes. Then rasters with calculated and classified values were transformed and merged into the one vector layer with attributes for the convenience of mapping.

As a result, the developed approach combines the strengths of both parameters, compensates for their shortcomings, and ensures the maximum preservation of useful information about the relief.

\subsection{Morphological mapping}

Until recently, a simple gradient scale with values from 0 to 1 was used for representation of morphometric parameters on the maps. But the gradient scale complicates the determination of values of certain parameters. So now we are working on development of a fundamentally new scale with separate steps. It is an important task, because classified scale not only 
simplifies the process of recognition of macrorelief forms but also makes maps more understandable.

Firstly, we used results of IQR calculation to find boundary values between different forms of macrorelief on the Moon and Mercury and distinguish different types of relatively flat surface: smooth plains, hummocky inter-crater plains and low parts of slopes. We aimed to achieve high coherence between our suggested values of roughness for smooth plains and estimates of geologists, studying hermian volcanism (Denevi et al., 2013).

Then we added areas, which were designated by RTP's values as sharp increase and decrease of heights - depressions and peaks. As a result, a morphological map of the selected region was created based on combination of two parameters (Fig. 6).

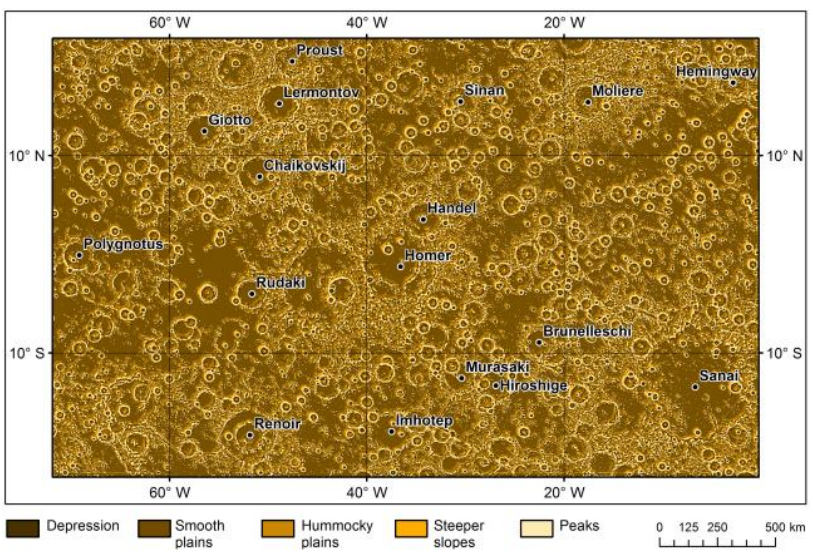

Figure 6. Morphological map of Kuiper quadrant; classified values of morphometric parameters clearly show small Sihtu plain and complex impact structures in the middle of rough inter-crater plains

As an experiment, the ranges of values for the classes used for Mercury did not change at all and fully corresponded to numbers obtained after for the Moon. Despite this, types of surface on the Moon were identified quite accurately. Morphological classification successfully separated rough areas from smooth ones, showed rims of craters and features inside of the largest ones (Fig. 7).

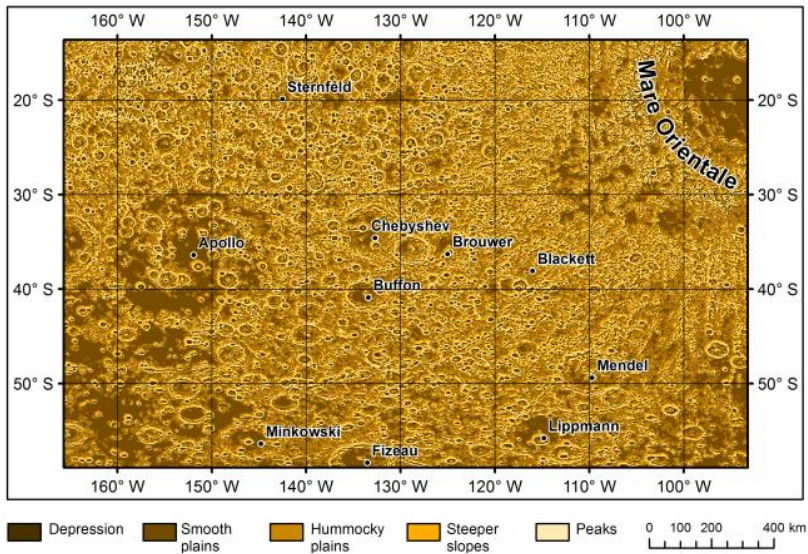

Figure 7. Morphological map of region of interest between

South Pole-Aitken basin and Mare Orientale; the DEM 's quality and classified values of RTP and IQR makes it possible to recognize many details

\subsection{Preliminary comparison of morphology of Mercury and the Moon on global level}

A comparative planetary analysis of the Moon and Mercury is a complex work, which can be done in different ways. We carry it out on the basis of comparing the distribution of areas occupied by the most common forms of macrorelief.

Primarily, surfaces of celestial bodies were divided into five parts by latitudes: two polar belts (from $90^{\circ}$ to $60^{\circ}$ ), two temperate belts (from $60^{\circ}$ to $20^{\circ}$ ) and one equatorial belt (from $20^{\circ} \mathrm{N}$ to $20^{\circ} \mathrm{S}$ ).

After that, a comparison of the percentage ratio of the areas occupied by certain forms of macrorelief to the total area of a particular latitudinal belt was made (Table 2). For clarity, two classes - the slopes of the hills and the peaks of the hills - were combined into one, which characterizing the uplands as a whole.

It is important to mention that in this part of study we used only one parameter - the IQR. This decision was made to concentrate on exploration of plains and other relatively flat regions. In the future, areas obtained by the second parameter RTP - also will be used to identify patterns in the distribution of depressions on celestial bodies.

\begin{tabular}{|l|c|c|c|}
\hline \multicolumn{1}{|c|}{$\begin{array}{c}\text { Celestial } \\
\text { body }\end{array}$} & $\begin{array}{c}\text { Smooth } \\
\text { plains }\end{array}$ & $\begin{array}{c}\text { Hummocky } \\
\text { plains }\end{array}$ & $\begin{array}{c}\text { Slopes and } \\
\text { peaks }\end{array}$ \\
\hline \multicolumn{4}{|c|}{ Northern polar belt $90^{\circ} \mathrm{N}-60^{\circ} \mathrm{N}$} \\
\hline Mercury & $73,2 \%$ & $21,7 \%$ & $5,1 \%$ \\
\hline The Moon & $16,87 \%$ & $41,77 \%$ & $41,37 \%$ \\
\hline \multicolumn{4}{|c|}{ Northern temperate belt $60^{\circ} \mathrm{N}-20^{\circ} \mathrm{N}$} \\
\hline Mercury & $45,03 \%$ & $43,47 \%$ & $11,5 \%$ \\
\hline The Moon & $33,75 \%$ & $35,34 \%$ & $30,94 \%$ \\
\hline \multicolumn{5}{|c|}{ Equatorial belt $20^{\circ} \mathrm{N}-20^{\circ} \mathrm{S}$} \\
\hline Mercury & $34,06 \%$ & $49,43 \%$ & $16.51 \%$ \\
\hline The Moon & $28,66 \%$ & $33,17 \%$ & $38.17 \%$ \\
\hline \multicolumn{5}{|c|}{ Southern polar belt $60^{\circ} \mathrm{S}-90^{\circ} \mathrm{S}$} \\
\hline Mercury & $28,94 \%$ & $51,77 \%$ & $19,28 \%$ \\
\hline The Moon & $21,46 \%$ & $43,31 \%$ & $35,23 \%$ \\
\hline \multicolumn{5}{|c|}{$44,02 \%$} & $43,87 \%$ & $12,11 \%$ \\
\hline Mercury & $10,71 \%$ & $45,96 \%$ & $43,33 \%$ \\
\hline The Moon &
\end{tabular}

Table 2. Distribution of areas within latitudinal belts, which occupied by the most common forms of macrorelief

Statistical calculations for Mercury have shown that the area of regions without significant roughness decreases as we move from the North Pole of the planet to the south. The largest percentage of smooth plains on Mercury is observed within the northern polar belt $(73.2 \%$ of the region's area), where the huge smooth volcanic formation Borealis Planitia is located.

This peculiarity of planetary macrorelief - the presence of large plain in the north and it's absents in the south - is also known on Mars. However, on the Moon, the area of smooth plains near the North Pole is relatively small $(16.87 \%$ versus $45.03 \%$ within the northern temperate belt). 


\subsection{Cryptomaria and "Cryptoplains"}

During the process of automatic allocating of plains on Mercury based on the results of IQR's calculations, specific areas were found (Fig. 8). These areas mostly correspond to smooth type of macrorelief by values of morphometric parameters, but do not coincide with territories marked by geologists as volcanic plains (Denevi et al., 2013).

Earlier, areas with similar features were discovered on the Moon - so-called cryptomaria. In the geological past of our satellite cryptomaria were ordinary maria (low-albedo plains of volcanic origin) but over the time they were strongly covered with fresh craters and ejecta. Therefore, they are not visible on the images now and can be found only by calculating the morphometric parameters of the relief.

We cannot claim that the observed areas on Mercury have the same origin as lunar cryptomaria. But there is a possibility that analogous morphological processes took place on Mercury too. We plan to continue the study of these "cryptoplains" in further works.

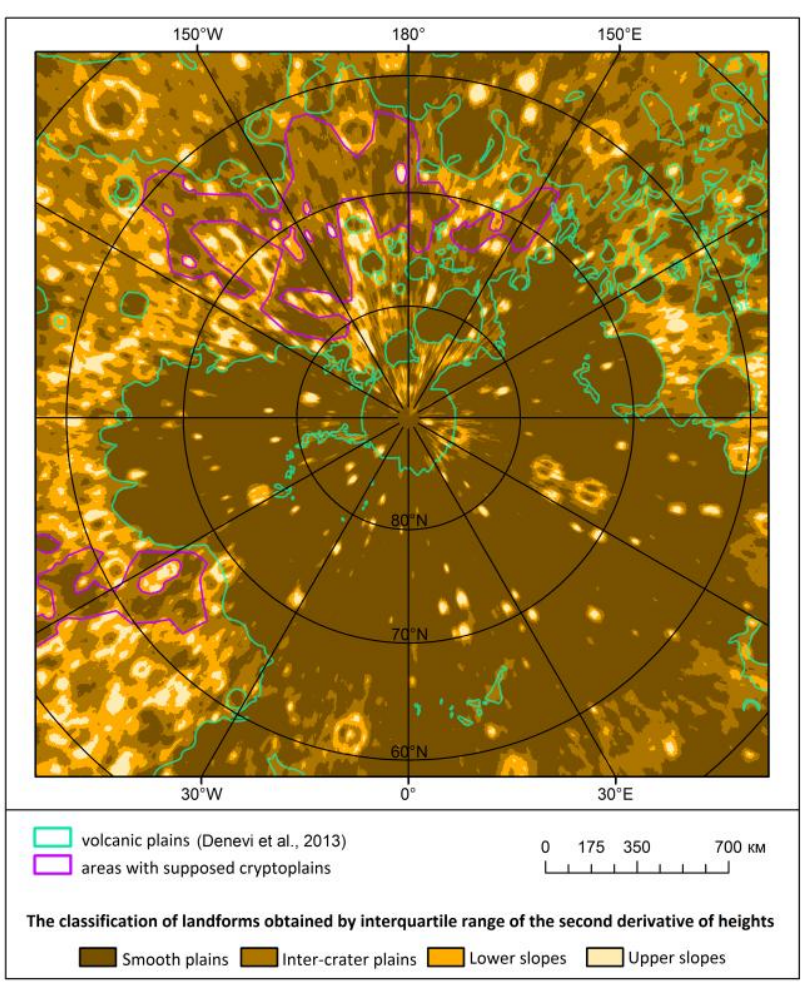

Figure 8. Map of the northern polar region of Mercury (projection: polar stereographic); classified values of IQR distinguish the smooth plains (turquoise) and areas of the supposed "cryptoplains" (magenta)

\section{CONCLUSIONS}

We calculated morphometric parameters at global and local levels for Mercury and the Moon, carried out a preliminary comparison of obtained values and morphological zoning for mapping purposes.

In process of work it became clear that two parameters are not enough to create a complete detailed morphological map. In future it is necessary to involve other parameters, for example, land-surface curvatures (Florinsky, 1998). That may give us the opportunity to simplify detection of more specific relief features (grooves on the Moon and scarps on Mercury) and create more complete classification of planetary relief forms.

Such results can be used to perform comparative planetological analysis at deeper level and process data of European mission to Mercury - BepiColombo - successfully launched in 2018.

\section{ACKNOWLEDGEMENTS}

A.Yu. Zharkova and M.M. Kolenkina were supported by Russian Foundation for Basic Research (RFBR), project № 1835-00334.

\section{REFERENCES}

Becker, K.J., Robinson, M.S., Becker, T.L., Weller, L.A., Edmundson, K.L. Neumann, G.A., Perry, M.E., Solomon, S.C., 2016. First Global Digital Elevation Model of Mercury. 47th LPSC, The Woodlands, Texas, 1903.

Denevi, B.W., Ernst, C.M., Meyer, H.M., Robinson, M.S., Murchie, S.L., Whitten, J.L., Head, J.W., Watters, Th.R., Solomon, S.C., Ostrach, L.R., Chapman, C.R., Byrne, P.K., Klimczak, Ch., Peplowski, P.N., 2013. The distribution and origin of smooth plains on Mercury. J Geophys Res, 118, 5, 891-907. doi.org/10.1002/jgre.20075.

Florinsky, I.V., 1998. Combined analysis of digital terrain models and remotely sensed data in landscape investigations. Progr. Phys. Geography, 22, 1, 33-60. doi.org/10.1177/030913339802200102

Florinsky, I.V., 2008. Global morphometric maps of Mars, Venus, and the Moon. Geospatial Vision: New Dimensions in Cartography. Lecture Notes in Geoinformation and Cartography. Berlin: Springer, 171-192. doi.org/10.1007/978-3540-70970-1_8.

Hawkins, S.E., Boldt, J.D., Darlington, E.H., Espiritu, R., Gold, R.E., Gotwols, B., Grey, M. P., Hash, C.D., Hayes, J.R., Jaskulek, S.E., Kardian, C.J., Keller, M.R., Malaret, E.R., Murchie, S.L., Murphy, P.K., Peacock, K., Prockter, L.M., Reiter, R.A., Robinson, M.S., Schaefer, E.D., Shelton, R.G., Sterner, R.E., Taylor, H.W., Watters, Th.R., Williams, B.D., 2007. The Mercury Dual Imaging System on the MESSENGER Spacecraft. Space Sci Rev, 131, 1-4, 247-338. doi.org/10.1007/s11214-007-9266-3.

Ivanov, M.A., Hiesinger, H., van der Bogert, C.H., Orgel, C., Pasckert, J.H., Head, J.W., 2018. Geologic history of the northern portion of the South Pole-Aitken basin on the Moon. $J$ Geophys Res-Planets, 123, 2585-

2612. doi.org/10.1029/2018JE005590.

Jenness, J., 2006. Topographic Position Index (TPI) v. 1.3a, Jenness Enterprices. url: http://www.jennessent.com/arcview/tpi .htm (accessed 8 April 2019).

Kokhanov, A.A., Bystrov, A.Y., Kreslavsky, M.A., Matveev, E.V., Karachevtseva, I.P., 2016. Automation of morphometric measurements for planetary surface analysis and cartography. In Int. Arch. Photogramm. Remote Sens. Spatial Inf. Sci., XLI-B4, 431-433. doi.org/10.5194/isprs-archives-XLI-B4-431-2016. 
Kreslavsky, M.A., Head, J.W., Neumann, G.A., Rosenburg, M.A., Aharonson, O., Smith, D.E., Zuber, M.T., 2013. Lunar topographic roughness maps from Lunar Orbiter Laser Altimeter (LOLA) data: Scale dependence and correlation with geologic features and units. Icarus, 226, 52-66. doi.org/10.1016/j.icarus.2013.04.027.

Kreslavsky, M.A., Head J.W., 2000. Kilometer-scale roughness of Mars: Results from MOLA data analysis. J Geophys Res, 105, E11, 26695-26712. doi.org/10.1029/2000JE001259.

Kreslavsky, M.A., Head, J.W., Neumann, G.A., Zuber, M.T., Smith, D.E., 2014. Kilometer-Scale Topographic Roughness of Mercury: Correlation with Geologic Features and Units. Geophysical research letters, 4, 23, 8245-8251. doi.org/10.1002/2014GL062162.

Preusker, F., Oberst, J., Stark, A., Matz, K-D., Gwinner, K., Roatsch, T., 2017. High-Resolution Topography from MESSENGER Orbital Stereo Imaging - The Southern hemisphere, EPSC Abstracts, 11, EPSC2017-591.

Robinson, M.S., Brylow, S.M., Tschimmel, M., Humm, D., Lawrence, S.J., Thomas, P.C., Denevi, B.W., BowmanCisneros, E., Zerr, J., Ravine, M.A., Caplinger, M.A., Ghaemi, F.T., Schaffner, J.A., Malin, M.C., Mahanti, P., Bartels, A., Anderson, J., Tran, T.N., Eliason, E.M., McEwen, A.S., Turtle, E., Jolliff, B.L., Hiesinger, H., 2010. Lunar Reconnaissance Orbiter Camera (LROC) instrument overview. Space Sci. Rev., 150, 1-4, 81-124. doi.org/10.1007/s11214-010-9634-2.

Rosenburg, M.A., Aharonson, O., Head, J.W., Kreslavsky, M.A., Mazarico, E., Neumann, G.A., Smith, D.E., Torrence, M.H., Zuber, M.T., 2011. Global surface slopes and roughness of the Moon from the Lunar Orbiter Laser Altimeter. J Geophys Res, 116, E02001. doi.org/10.1029/2010JE003716.

Scholten F., Oberst J., Matz K.-D., Roatsch T., Wählisch M., Speyerer E.J., Robinson M.S., 2012. GLD100: The near-global lunar $100 \mathrm{~m}$ raster DTM from LROC WAC stereo image data. J Geophys Res, 117, E00H17. doi.org/10.1029/2011JE003926.

Zharkova, A.Yu., Kokhanov, A.A., Kolenkina, M.M., 2018. Analysis and global mapping of statistical parameters of Mercury relief characteristics. EPSC Abstracts, 12, EPSC2018-311. 